\title{
Reduced Epidermal Growth Factor Receptor Expression in Hypohidrotic Ectodermal Dysplasia and Tabby Mice
}

\author{
Gabriel A. Vargas, ${ }^{\star}$ Emanuelle Fantino, ${ }^{\ddagger}$ Carlos George-Nascimento, J. Jay Gargus, ${ }^{\ddagger \S}$ and Harry T. Haigler ${ }^{\star \ddagger}$ \\ $*$ Department of Biological Chemistry, ${ }^{\ddagger}$ Department of Physiology and Biophysics, and ${ }^{\S}$ Division of Human Genetics, Department of \\ Pediatrics, University of California Medical School, Irvine, California 92715; and ${ }^{\|}$Chiron Corporation, Emeryville, California 94608
}

\begin{abstract}
Patients with hypohidrotic ectodermal dysplasia (HED) and Tabby $(\mathrm{Ta})$ mice lack sweat glands and there is compelling evidence that these phenotypes are caused by mutations in the same highly conserved but unidentified X-linked gene. Previous studies showed that exogenous epidermal growth factor (EGF) reversed the $\mathrm{Ta}$ phenotype but the EGF status in HED patients has not been studied at all. Studies reported herein investigated the hypothesis that the EGF signaling pathway is involved in HED/Ta. Fibroblasts from HED patients had a two- to eightfold decrease in binding capacity for ${ }^{125} \mathrm{I}$-labeled EGF, a decreased expression of the immunoreactive $170-\mathrm{kD}$ EGF receptor (EGFR) protein, and a corresponding reduction in EGFR mRNA. Reduced expression of the EGFR also was observed in $\mathrm{Ta}$ fibroblasts and liver membranes. Other aspects of the EGF signaling pathway, including EGF concentration in urine and plasma, were normal in both HED patients and Ta mice. We propose that a decreased expression of the EGFR plays a causal role in the HED/Ta phenotype. (J. Clin. Invest. 1996. 97:2426-2432.) Key words: epidermal growth factor • hypohidrotic ectodermal dysplasia - epidermal growth factor receptor $\bullet$ Tabby mouse $\bullet$ morphogenesis
\end{abstract}

\section{Introduction}

Hypohidrotic (anhidrotic) ectodermal dysplasia (HED ${ }_{1}^{1}$ EDA, Christ-Siemens-Touraine syndrome, MIM 305100) is an $\mathrm{X}$-linked recessive disorder of morphogenesis characterized by hypoplasia of hair, teeth, and eccrine sweat glands (1). The inability to sweat results in episodes of infantile hyperthermia, producing the neurological sequelae and mortality associated with the phenotype. HED is the most common of the ectodermal dysplasia syndromes, and it appears as a homogeneous phenotype without apparent underlying genetic heterogeneity (2).

Address correspondence to Harry T. Haigler, Department of Physiology and Biophysics, University of California Medical School, Irvine, CA 92715. Phone: 714-824-6304; FAX: 714-824-6304; E-mail: Hhaigler@uci.edu

Received for publication 25 February 1996 and accepted in revised form 7 March 1996.

1. Abbreviations used in this paper: EGFR, EGF receptor; HED, hypohidrotic ectodermal dysplasia.

J. Clin. Invest.

(C) The American Society for Clinical Investigation, Inc.

0021-9738/96/06/2426/07 \$2.00

Volume 97, Number 11, June 1996, 2426-2432
The HED gene has been localized within the Xq12-13.1 region of the $\mathrm{X}$ chromosome by linkage analysis $(3,4)$, the study of males with the characteristic phenotype and microdeletions within the interval (5), and the study of translocation breakpoints in females with the characteristic phenotype and X;autosome translocations (6). However, neither the molecular pathogenesis of HED nor the nature of the HED gene has been determined.

A mutation within the syntenic region of the mouse $\mathrm{X}$ chromosome causes the Tabby phenotype ( $T a)$, which shares the features of hypoplastic hair, teeth, and eccrine sweat glands with HED (7). In fact, the first human microdeletion causing HED was disclosed with a probe from the murine $T a$ locus, suggesting that the $T a$ and HED phenotypes originate from mutations within the same conserved HED/Ta gene (5).

Two additional prominent features of the $\mathrm{Ta}$ phenotype are delayed eyelid opening and incisor eruption, effects of the mutation opposite to those classically elicited from mice in response to epidermal growth factor (EGF) (8). This interpretation was dramatically supported by finding both phenotypic characteristics to be reversed postnatally by treatment with high systemic doses of EGF (8), a treatment that also, remarkably, resulted in the induction of functional eccrine sweat glands (9). However, like HED, neither the pathogenesis of $T a$ nor the nature of the $T a$ gene has been determined.

While the molecular mechanism of the effect of EGF on $T a$ remains to be defined, the facts that the hallmarks of the mutant phenotype are manifest in classical EGF-responsive tissue and that the mutant phenotype is reversed by EGF treatment suggest that the pathophysiological mechanism involves some aspect of the EGF signaling pathway. The most obvious candidates in this pathway, the EGF receptor (EGFR) and its known ligands (EGF, TGF- $\alpha$, amphiregulin, heparin-binding EGF, and betacellulin), are unlikely to be directly involved because the X chromosomal map position of the Ta mutation $(6,8)$ is not consistent with the autosomal location of these loci (10).

Although the EGF status of HED patients has not been investigated previously, the homology of the $T a$ and HED phenotypes and the syntenic relationship of the two loci suggest that HED shares a common molecular pathophysiology with $T a$, and further, that HED might benefit from similar pharmacological intervention. For this reason, we undertook a study of the EGF signaling pathway in HED and $T a$. In this paper we compared wild-type with either $T a$ or HED and found indistinguishable concentrations and activities of EGF, while EGFR expression is decreased in an allele-specific fashion in both human and mouse mutants.

\section{Methods}

Case histories. RV is a 3-yr-old Hispanic male. This child presented in infancy with a classical picture of X-linked anhidrotic ectodermal dysplasia. The patient has a positive family history. His mother's sis- 
ter had two affected sons, one of whom died at 4 mo of age, and his mother's maternal uncle is affected. None of the female relatives are affected. The patient himself has the characteristic phenotype including the abnormal facies, sparse hair, absent eyebrows, chronic dryness of oral, nasal, and pharyngeal mucosa, and absent teeth. Before diagnosis he had been repeatedly hospitalized for hyperthermia.

DW is a 12-yr-old male followed at the University of California, San Diego. He has a positive family history with three maternal uncles who are affected. He has features consistent with HED including sparse hair, conical teeth, lack of sweat glands, exceedingly sparse eyebrows, and soft, smooth hairless skin.

Mice. Breeder pairs of $T a-\mathrm{C} / 6 \mathrm{~J}$ mice were purchased from The Jackson Laboratory (Bar Harbor, ME, catalogue No. JR0338) and used to establish a colony. Wild-type mice used as controls for experiments reported herein were normal males from the same litters as the Ta males.

Cell culture. HED fibroblasts were obtained from RV and DW by dermal biopsy and were cultured in $10 \%$ fetal calf serum in DME. Normal diploid human fibroblasts were obtained either from dermal biopsy or from foreskin. Experimental cell number was determined using a Coulter counter (Coulter Corp., Hialeah, FL) and the protein content of cell extracts was measured using a bicinchoninic acid kit (Pierce, Rockford, IL). AnLy cells (GM00705A, see reference 11) were obtained from the NIGMS cell repository managed by Coriell Research Institute (Camden, NJ).

EGF iodination. Human EGF, $10 \mu \mathrm{g}$ (Chiron Corp., Emeryville, CA), was labeled $\left(2-2.5 \times 10^{5} \mathrm{cpm} / \mathrm{ng}\right)$ with ${ }^{125} \mathrm{I}$ using the chloramine T procedure (12). ${ }^{125} \mathrm{I}$-Labeled mouse EGF was purchased from Amersham (Arlington Heights, IL).

Membrane isolation. Liver membranes were prepared from 30-d-old male wild-type or $T a$ mice by a published method (13).

EGF binding assay. The binding of the indicated concentrations of ${ }^{125} \mathrm{I}$-EGF to confluent cultures of fibroblasts in $16-\mathrm{mm}$ dishes ( $\sim 125,000$ cells/dish; $1 \mathrm{~h}$ of incubation at $4^{\circ} \mathrm{C}$ ) was determined as described previously (12). Nonspecific binding was measured in replicate cultures that contained a large excess $(1.0 \mu \mathrm{M})$ of unlabeled EGF. Nonspecific binding was approximately the same in normal and HED fibroblasts. In normal fibroblasts nonspecific binding was $\sim 5 \%$ of the total binding at the highest concentration of ${ }^{125} \mathrm{I}-\mathrm{EGF}$ tested. All data are reported as specific binding. Parallel dishes were analyzed for protein and cell number.

The binding of ${ }^{125} \mathrm{I}$-EGF to liver membranes $(65 \mu \mathrm{g}$ protein in $0.25 \mathrm{ml}$ buffer; $1 \mathrm{~h}$ of incubation at room temperature) was measured as described previously (13). Nonspecific binding was measured in the presence of a large excess of unlabeled EGF $(4 \mu \mathrm{g})$. Nonspecific binding was $\sim 5 \%$ of the total binding at the highest concentration of ${ }^{125}$ I-EGF tested.

Internalization. Monolayer cultures of HED and normal fibroblasts were labeled with ${ }^{125} \mathrm{I}-\mathrm{EGF}(2 \mathrm{ng} / \mathrm{ml})$ at $4^{\circ} \mathrm{C}$, unbound hormone was removed, then cells were warmed to $37^{\circ} \mathrm{C}$ for 3 or $9 \mathrm{~min}$. The location of the cell-bound hormone was determined by stripping with acetic acid as described previously (14). The results are expressed as the percentage of cell-associated radioactivity at a given time point that was not removed by the acid wash, i.e., the internalized fraction.

Thymidine incorporation. The biological activity of EGF was measured as its ability to stimulate the incorporation of $\left[{ }^{3} \mathrm{H}\right]$ thymidine in quiescent cultures of human fibroblasts by published methods (15).

Immunoblotting. Preparation of extracts of cultured cells $(100 \mu \mathrm{g}$ protein/lane), SDS-PAGE, transfer to polyvinylidene difluoride (Immobilon) membranes, incubation with antiserum, incubation with ${ }^{125}$ I-labeled protein $\mathrm{A}$, and visualization by autoradiography were performed as described previously (16). The same methods were used to analyze extracts of liver membranes ( $88 \mu \mathrm{g}$ protein/lane). Antibody against either the EGFR $(2 \mu \mathrm{g} / \mathrm{ml}$ affinity-purified antibody raised against a peptide corresponding to amino acids 1005-1016 of the human EGFR; catalogue No. SC-03, Santa Cruz Biotechnology Inc., Santa Cruz, CA; this antibody reacts with both the human and mouse EGFR) or phosphotyrosine (PY-20; Sigma Chemical Co., St. Louis, MO) was obtained from commercial sources.
Table I. EGF in Mouse Body Fluids

\begin{tabular}{lcc}
\hline \multicolumn{1}{c}{ Source } & Urine & Plasma \\
\hline Wild-type & $1300 \pm 583 \mathrm{ng} / \mathrm{ml}$ & $0.5 \pm 0.3 \mathrm{ng} / \mathrm{ml}$ \\
Tabby & $970 \pm 404 \mathrm{ng} / \mathrm{ml}$ & $0.6 \pm 0.2 \mathrm{ng} / \mathrm{ml}$ \\
Published values & $1400 \mathrm{ng} / \mathrm{ml}$ & $2 \mathrm{ng} / \mathrm{ml}$ \\
\end{tabular}

The immunoreactive EGF in mouse urine and plasma was measured as described in Methods. Duplicate samples from five wild-type and five $T a$ mice were assayed. The values obtained $(\operatorname{mean} \pm \mathrm{SD})$ were not significantly different for wild-type or $T a$ mice. The immunoreactive EGF measured in the urine was similar to previously reported values but the measured level in the plasma was slightly lower than previously reported $(30,31)$. The small difference between the measured and published value probably is a reflection of different assay methods rather than a real biological difference.

RNA analysis. Total RNA was isolated using a commercial guanidinium isothiocyanate extraction method (QIAGEN Inc., Chatsworth, CA). RNA (20 $\mu$ g determined spectrophotometrically) was immobilized on nitrocellulose membranes (Costar Corp., Cambridge, MA) and probed under high stringency hybridization and wash conditions with a 40-mer (catalogue No. 0N127; Oncogene Science Inc., Manhasset, NY) specific for the $5^{\prime}$ untranslated region of the human EGFR gene. The probe was end-labeled with ${ }^{32} \mathrm{P}$ using T4 polynucleotide kinase. To normalize amounts of RNA, the blot was rehybridized with a human $\beta$-actin riboprobe. As a negative control, mouse total RNA was loaded on adjacent lanes and did not react with the human EGFR probe.

EGF radioimmunoassay. The immunoreactive EGF levels were determined using radioimmunoassay kits containing antisera specific for either human or mouse EGF (Biomedical Technologies, Inc., Stoughton, MA). Samples of urine and plasma were assayed directly with detection limits of $\sim 0.2 \mathrm{ng} / \mathrm{ml}$ EGF in both kits. Both antisera are very specific for EGF and neither cross-reacts with TGF- $\alpha$.

\section{Results}

EGF in HED and Ta body fluids. As the first test of the hypothesis that a defect in the EGF signaling pathway is associated with the HED/Ta phenotype, we evaluated the levels of EGF in body fluids. We observed no significant differences between wild-type and $T a$ mice with respect to the levels of immunoreactive EGF in plasma or urine (Table I). Likewise, the levels of EGF in plasma and urine from two children with

Table II. EGF in Human Body Fluids

\begin{tabular}{lcc}
\hline \multicolumn{1}{c}{ Source } & Urine & Plasma \\
\hline Normal & $70 \mathrm{ng} / \mathrm{ml}$ & $0.6 \mathrm{ng} / \mathrm{ml}$ \\
RV & $35 \mathrm{ng} / \mathrm{ml}$ & $1.5 \mathrm{ng} / \mathrm{ml}$ \\
DW & $50 \mathrm{ng} / \mathrm{ml}$ & $1.8 \mathrm{ng} / \mathrm{ml}$ \\
Published values & $25-88 \mathrm{ng} / \mathrm{ml}$ & $0.4-1.5 \mathrm{ng} / \mathrm{ml}$ \\
& & \\
\hline
\end{tabular}

The immunoreactive EGF in samples of urine and plasma from HED patients RV and DW and from a normal child was measured as described in Methods. The values obtained from triplicate aliquots differed by $<15 \%$. The EGF levels in normal and HED children did not differ significantly and were within the range previously reported (32-34). 


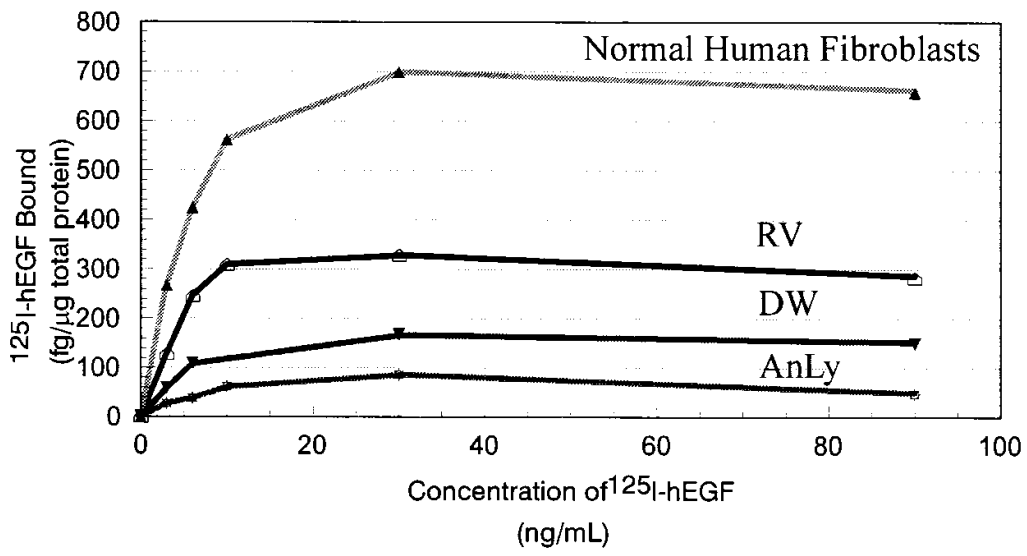

Figure 1. Binding of ${ }^{125}$ I-EGF to normal and HED fibroblasts. The indicated concentrations of ${ }^{125} \mathrm{I}$-labeled human EGF were incubated at $4^{\circ} \mathrm{C}$ with cultures of either normal human fibroblasts or fibroblasts from HED patients RV, DW, or AnLy. The specific binding was measured as described in Methods. The AnLy binding curve, along with control fibroblasts, has been repeated four times with a six- to ninefold reduction in ${ }^{125}$ I-EGF binding seen each time. The binding of ${ }^{125} \mathrm{I}-$ EGF to DW and RV cultures has been compared with normal fibroblasts two and three times, respectively, with results similar to those reported in this figure. The values represent the average of triplicate cultures and varied by $<10 \%$.
HED (RV and DW; see Methods for description) were not significantly different from normal (Table II). To determine the biological activity of this EGF, urine containing a known amount of immunoreactive EGF from a patient and a control was used to stimulate mitogenesis in quiescent fibroblasts. The amount of biologically active EGF measured was in good agreement with the measured immunoreactivity (data not shown). Control experiments using an antiserum that inactivates EGF showed that the only mitogen detected in our assay was EGF.

Several EGF-like peptides that bind to the EGFR have been identified (10) and more may remain undetected. Because of this complexity, it is not formally possible to definitively establish that all of the ligands for the EGF signaling pathway are normal. However, our experiments did not detect any problems with the classical ligand for this pathway. Thus, experiments described in the next two sections focused on the status of the EGFR in HED patients and Ta mice.

EGFR in HED patients. We placed into culture dermal fibroblast from two classical familial HED patients, RV and DW. We also studied cultured fibroblasts from a previously reported HED patient AnLy, a female with HED and an X;9 reciprocal translocation (11). Based on prior experience with such translocations (17), it is likely that the HED gene in AnLy has been disrupted by this event (11). To focus on the interaction of the hormone with the cell surface receptor, the binding experiments were performed at $4^{\circ} \mathrm{C}$ to prevent receptor-mediated endocytosis (15). Fig. 1 shows that there was reduced binding of ${ }^{125}$ I-EGF in all of the HED fibroblasts relative to normal human fibroblasts. In AnLy fibroblasts there was an eightfold reduction in binding at the highest hormone

Table III. Internalization of ${ }^{125} I-E G F$

\begin{tabular}{|c|c|c|}
\hline \multirow{2}{*}{$\frac{\text { Time }}{\text { Minutes }}$} & \multicolumn{2}{|c|}{$\begin{array}{c}\text { Internalization } \\
\text { (percent of total bound) }\end{array}$} \\
\hline & HED fibroblasts & Normal fibroblasts \\
\hline 3 & 61 & 70 \\
\hline 9 & 76 & 78 \\
\hline
\end{tabular}

The internalization of ${ }^{125}$ I-EGF by duplicate cultures of normal or HED $(\mathrm{RV})$ fibroblasts was measured as described in Methods. The results are expressed as the percentage of cell-associated radioactivity at a given time point that was not removed by the acid wash, i.e., the internalized fraction. concentration tested. Fig. 1 expresses the binding on a per microgram of cellular protein basis, but similar relative binding capacities are observed when the data are plotted on a per cell basis because the amount of protein per cell was the same in normal and HED cells. In a separate set of experiments, an independent culture of normal human dermal fibroblasts bound nine times the amount of ${ }^{125}$ I-EGF bound by AnLy cells at the highest concentration of hormone tested (results not shown).

The reduced binding in HED fibroblasts appeared to be due to a reduced number of receptors rather than a change in binding affinity. Scatchard plot analysis of the normal and RV binding curves showed that both cultures had similar affinities $\left(3-4 \times 10^{-10} \mathrm{M}\right)$ for the hormone, but differed in the number of receptors $(59,000$ and 29,000 receptors per cell for normal and RV fibroblasts, respectively). DW and AnLy cultures were excluded from Scatchard analysis because binding was too low to obtain meaningful results.

We compared the receptor-mediated endocytosis of ${ }^{125} \mathrm{I}$ EGF in cultures of RV and normal fibroblasts using published methods (14). The rates of internalization in both cultures were indistinguishable and matched published values for normal fibroblasts (Table III). Thus, this cellular pathway appears to be normal in HED cells.

We also examined EGFR expression in normal and AnLy fibroblasts by Western blot analysis. The expected immunoreactive band at $170 \mathrm{kD}$ was observed in extracts from normal fibroblasts (Fig. 2, lane $a$ ) but no corresponding band was de-

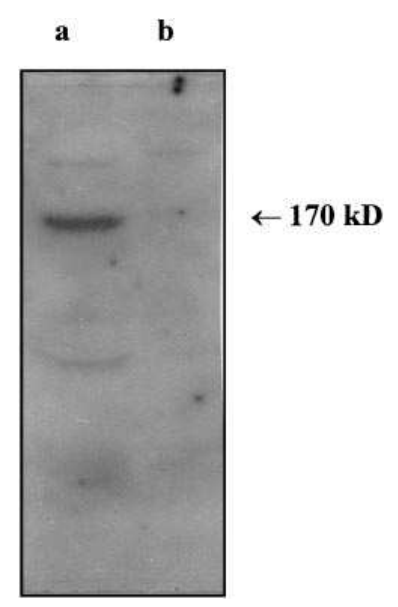

Figure 2. Immunoblot analysis of EGFR in normal and HED fibroblasts. Aliquots ( $0.1 \mathrm{mg}$ protein) of extracts of cultures of either AnLy or normal human fibroblasts were subjected to SDS-PAGE $(7.5 \%$ acrylamide) and then transferred to Immobilon membranes. The membrane was then incubated with an antibody specific for the EGFR and immunoreactive protein was visualized by incubating with ${ }^{125}$ I-labeled protein A followed by autoradiography as described in Methods. The $170-\mathrm{kD}$ band corresponds to the known size of the EGFR. Lane $a$, normal fibroblasts; lane $b$, AnLy cells. 
A. B.

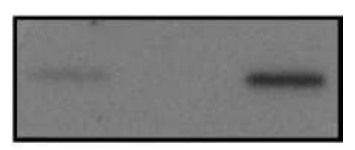

C. D.

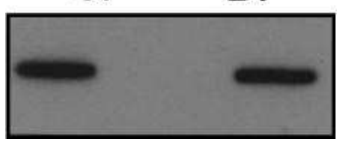

Figure 3. Expression of mRNA for the EGFR in normal and HED fibroblasts. Total RNA was isolated by guanidinium isothiocyanate extraction from cultures of either normal or AnLy fibroblasts. RNA $(20 \mu \mathrm{g})$ was transferred to nitrocellulose and the membrane was probed under high stringency hybridization and wash procedures with a ${ }^{32} \mathrm{P}$-labeled probe corresponding to the $5^{\prime}$ untranslated sequences of the human EGFR gene as described in Methods. The membrane was reprobed with a human $\beta$-actin probe as a control. $A$ and $B$, EGFR probe; $C$ and $D, \beta$-actin probe; $A$ and $C$, AnLy fibroblasts; $B$ and $D$, normal fibroblasts.

tectable in AnLy cells (Fig. 2, lane $b$ ). Thus, the reduced binding of ${ }^{125}$ I-EGF observed in HED fibroblasts (Fig. 1) appears to be due to a reduction in the expression of the receptor rather than expression of an abnormal receptor.

The relative expression of mRNA encoding the EGFR in HED cells was evaluated. Densitometric scanning of the autoradiogram shown in Fig. 3 indicated that there is a ninefold reduction in EGFR mRNA in AnLy relative to normal fibroblasts. These data indicate that the reduced EGFR expression in HED cells is either due to decreased transcription or due to increased EGFR mRNA degradation.

As a control to determine whether the reduction in expression of the EGFR was specific, we compared the expression of

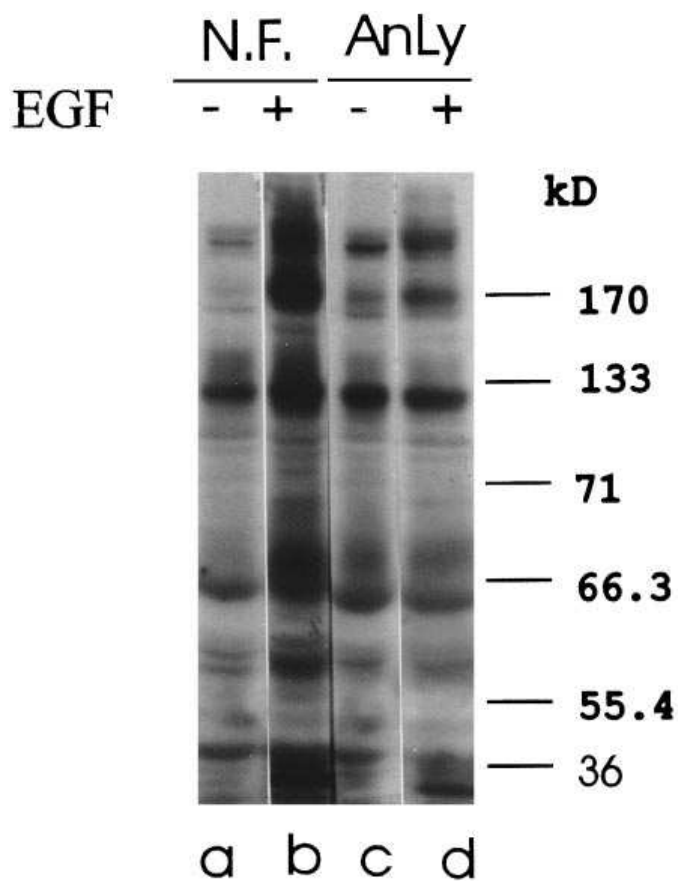

Figure 4. Tyrosine-protein kinase activity in intact normal and HED fibroblasts. Extracts from control and EGF-stimulated cultures of normal or AnLy fibroblasts were subjected to SDS-PAGE and then transferred to Immobilon membranes. The membrane was then incubated with an antibody against protein phosphotyrosine (PY20) and immunoreactive protein was visualized by incubating with ${ }^{125} \mathrm{I}$-labeled protein A followed by autoradiography as described in Methods. The major phosphorylated band at $170 \mathrm{kD}$ corresponds to the size of the EGFR.
FGF receptor-1 and c-Harvey ras mRNAs in normal and AnLy fibroblasts using methods described in the legend to Fig. 3 . We found no significant differences in either FGF receptor-1 or c-Harvey ras mRNAs in AnLy fibroblasts compared with normal fibroblasts (data not shown).

After the hormone binds, the first step in the cellular EGF signaling pathway is activation of the protein-tyrosine kinase activity that is intrinsic to the EGFR (18). We evaluated this activity in normal and AnLy fibroblasts after stimulation by EGF. Intact cells that had been incubated in either the presence or absence of EGF were extracted, subjected to PAGE, and blots of the gel were probed with an antibody against phosphotyrosine. Fig. 4 shows the expected $170-\mathrm{kD}$ band corresponding to the autophosphorylated EGFR in EGF-treated normal fibroblasts (lane $b$ ), but the $170-\mathrm{kD}$ band was greatly diminished in intensity in AnLy cells (lane $d$ ).

EGFR in Ta mice. The following experiments were performed to evaluate EGFR expression in $\mathrm{Ta}$-C/6J mice. Dermal fibroblasts from $T a$ mice bound $\sim 3.3$-fold less ${ }^{125}$ I-EGF than fibroblasts from wild-type mice (Fig. 5). We also measured ${ }^{125}$ I-EGF binding to membranes from liver, an organ which is known to have a high concentration of EGFRs and to respond to exogenous EGF (13). Fig. 6 shows that wild-type membranes had the affinity and binding capacity expected from previous reports (13) but membranes from Ta mice bound less ${ }^{125}$ I-EGF. Scatchard analysis (not shown) showed that the affinity was the same in both samples but the number of receptors per microgram of membrane protein was reduced 2.5 -fold in the $T a$ membranes. Western blot analysis of parallel liver membrane samples revealed a significant reduction (threefold as measured by densitometry) in the immunoreactive receptor in the $T a$ mouse (Fig. 7).

\section{Discussion}

We examined several of the key steps in the EGF signaling pathway in HED patients and $T a$ mice to test the hypothesis that a signaling defect in this pathway was associated with these phenotypes. The same abnormality, a decreased level of EGFR expression, was the only abnormality detected in either. Finding that these two phenotypes share a similar biochemical lesion suggests that they share the same molecular mechanism of pathogenesis, greatly strengthening the notion that they reflect mutations in the same evolutionarily conserved and syntenic gene, the HED gene. Compared with normal fibroblasts, RV, DW, and AnLy fibroblasts had a two-, four-, and ninefold reduction in ${ }^{125}$ I-EGF binding capacity, respectively (Fig. 1). A comparable decrease in ${ }^{125}$ I-EGF binding capacity also was observed in cultured dermal fibroblasts $(\sim 3.3$-fold $)$ and liver membranes ( $\sim 2.5$-fold) from $T a$ mice (Figs. 5 and 6 ). The affinity of the receptors that were expressed in HED/Ta cells appeared to be normal, thereby suggesting that the decreased binding was caused by a decrease in the number of cell surface receptors. This interpretation was supported by further analysis of the AnLy fibroblasts which showed that expression of immunoreactive EGFR (Fig. 2) and EGFR mRNA (Fig. 3) was reduced to a similar extent as the ${ }^{125}$ I-EGF binding.

Since prior studies have shown that most familial HED alleles are likely to be point mutations $(5,19)$, it is interesting to note that the reduction in EGF binding capacity was greatest in AnLy fibroblasts, cells that likely contain a disrupted HED gene (11). The reduction was less severe in fibroblasts which 


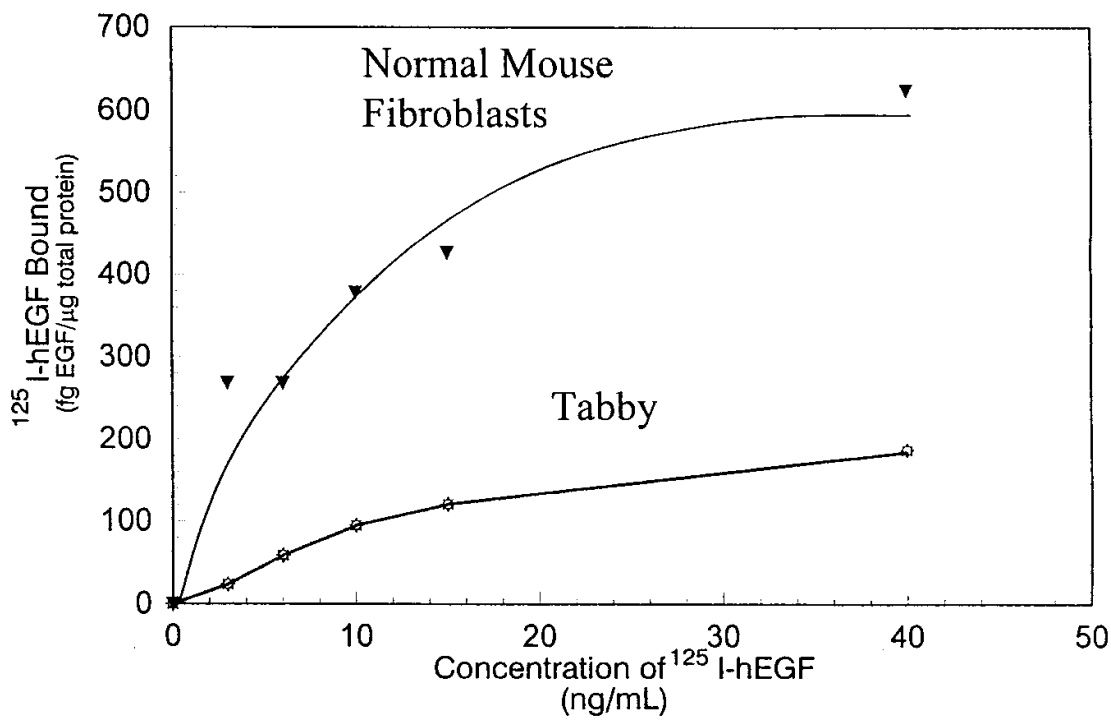

Figure 5. Binding of ${ }^{125}$ I-EGF to normal and $\mathrm{Ta}$ mouse fibroblasts. The indicated concentrations of ${ }^{125}$ I-EGF were incubated at $4^{\circ} \mathrm{C}$ with cultures of dermal fibroblasts from either wild-type or $T a$ mice. The specific binding was measured as described in Methods. The values represent the average of duplicate cultures and varied by $<10 \%$. presumably contain point mutations in the HED gene (familial HED patients RV and DW and the $T a-\mathrm{C} / 6 \mathrm{~J}$ mice) and thus may express proteins that are less functionally impaired than the AnLy HED gene product. Ultimately it should prove valuable to develop a correlation between the severity of the clinical phenotype, the biochemical phenotype, and the HED genotype.

It is interesting to speculate concerning the function of the HED gene in light of the observation that EGFR expression is reduced in HED/Ta. Clearly the EGFR gene is not the HED gene because these two genes map to separate chromosomes (18). Our functional data are consistent with these genetic data in that they indicate that the limited amount of EGFR protein which is expressed appears normal in HED/Ta. Since we observed a decreased level of the mRNA which encodes the EGFR, the lesion appears to cause this mRNA to be either transcribed at a reduced rate or degraded at a more rapid rate than normal. Previous studies of other inborn errors in mammalian morphogenesis have frequently identified transcription factors as the disease-causing gene (20). Thus, a transcription factor that regulates the expression of the EGFR gene is a likely candidate for the HED/Ta gene. If this were the case, one would speculate that the transcription of other genes might also be affected in HED/Ta. However, the defect is at least relatively selective for the EGFR as we observed normal transcription of the three other mRNAs we examined.

We propose that the decreased expression of the EGFR plays a causal role in the HED/Ta phenotype. Recently defined mutations in the EGF signaling pathway in both classical mutant and transgenic mice set the foundation for this paradigm. The phenotype of mice lacking TGF- $\alpha$, a ligand for the EGFR, primarily is restricted to "wavy" hair and whiskers (21). The waved-2 mouse has a similar phenotype to the TGF$\alpha$-deficient mouse and was shown recently to be caused by a mutation in the EGFR which partially inactivated its intrinsic kinase activity 5-10-fold (22). Pharmacological amounts of exogenous EGF caused a dose-dependent in vivo increase in EGFR tyrosine kinase activity (22), a response conceptually analogous to correction of the $T a$ phenotype with exogenous EGF (9). Another recent study has indicated that even small changes in EGFR number, such as the twofold decrease seen in RV, can cause significant phenotypic changes. For example, a 2.5-fold change in EGFR expression in retinal cells caused striking changes in cell developmental fate (23). Together, these studies establish a framework consistent with the proposal that modest changes in EGFR activity or number have the potential to alter phenotype, therefore having the potential to play a causal role in the HED/Ta phenotype.

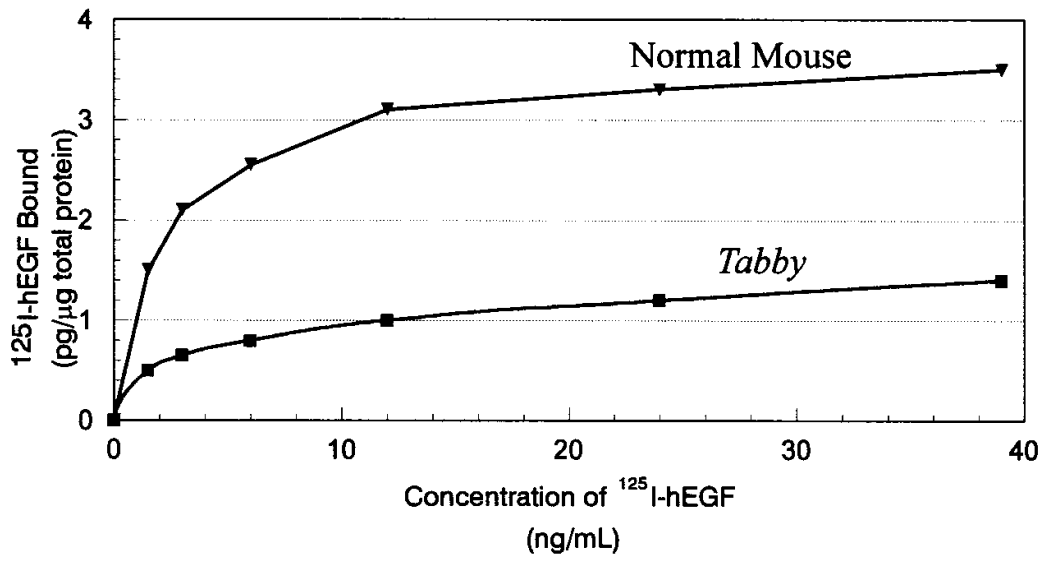

Figure 6. Binding of ${ }^{125}$ I-EGF to membranes from liver of normal and $\mathrm{Ta}$ mice. The indicated concentrations of ${ }^{125}$ I-EGF were incubated with membranes from either wild-type or $T a$ mice. The specific binding was measured as described in Methods. The values represent the average of duplicate reactions and varied by $<10 \%$. 


\section{Wt Tabby}

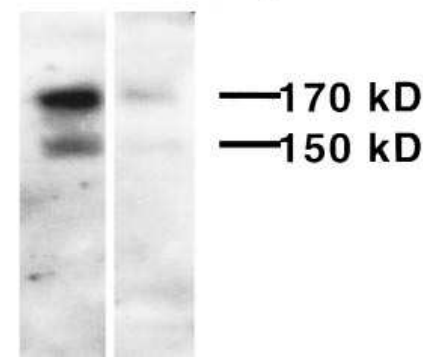

Figure 7. Immunoblot analysis of EGFR in liver membranes from wild-type and $T a$ mice. Aliquots ( $88 \mu \mathrm{g}$ protein) of liver membranes from wildtype or $T a$ mice were subjected to SDS-PAGE $(7.5 \%$ acrylamide) and then transferred to Immobilon. Then the Immobilon was incubated with an antibody specific for the EGFR and immunoreactive protein was visualized by incubating with ${ }^{125}$ I-labeled protein A followed by autoradiography as described in Methods. The 170-kD band corresponds to the known size of the EGFR. The 150-kD band corresponds to the size of the EGFR following a proteolytic clip that has been observed previously (35).

Since the EGFR is expressed in a wide range of tissues, there are in principle two different mechanisms by which the $\mathrm{HED} / \mathrm{Ta}$ phenotype could be confined to the limited number of epidermal structures in which it is manifest. This could reflect either the tissue-specific nature of the EGFR expression defect, such as might be conferred by a tissue-specific transcription factor (20), or it could reflect a generalized defect in EGFR expression, with the affected tissues being those most sensitive to a reduction in EGFR activity. Our data best support the latter interpretation. The defect in EGFR expression in HED/Ta seems not to be tissue-specific in that it was observed in both fibroblasts (Figs. 1 and 5) and liver (Fig. 6), cell types not obviously manifesting the phenotype. In addition, the epidermal tissues affected by the phenotype are likely to be those most sensitive to EGFR signaling; clearly they are the classical targets of EGF (24). The effects of EGF on sweat gland development have not been studied in detail, however, ultrastructural studies have localized EGF to sweat glands (25) and EGFRs have been localized to keratinocytes in developing human skin (26). Again, the phenotype of murine EGFR mutants, in this case EGFR knockouts in transgenic mice (2729), supports this model of graded tissue sensitivity. Homozygotes for a knockout null allele exhibit a remarkable range of strain-specific, fully penetrant, nonoverlapping phenotypes. This suggests that the sensitivity of different tissues to even the complete absence of EGFR is set by its epistatic interaction with multiple loci. In the least sensitive strains, i.e., those with the mildest manifestations, the null phenotype includes hair and eyelid hypoplasia, suggesting they are among the most sensitive tissues. However, with this marked reduction in EGFR expression, epithelial development is impaired in several other organs as well.

In summary, we investigated the EGF signaling pathway in $T a$ mice and HED patients and documented a reduction in expression of the EGFR. We propose that the HED/Ta phenotype is caused by defective developmental signals due to decreased EGFR expression and suggest that the HED/Ta mutation offers a unique opportunity to study the role of the EGFR in the regulation of cell differentiation.

\section{Acknowledgments}

We thank Dr. L. Bird at Children's Hospital (San Diego, CA) for providing DW samples.
This work was supported by a grant from the American Cancer Society (BE\#254 to H.T. Haigler and J.J. Gargus), by the University of California, Irvine, Cancer Center, and by a fellowship from the University of California, Irvine, Medical Scientist Program (to G.A. Vargas).

\section{References}

1. Clarke, A., D. Phillips, R. Brown, and P. Harper. 1987. Clinical aspects of X-linked hypohidrotic ectodermal dysplasia. Arch. Dis. Child. 62:989-996.

2. Zonana, J. 1993. Hypohidrotic (anhidrotic) ectodermal dysplasia: molecular genetic research and its clinical applications. Semin. Dermatol. 12:241-246.

3. Zonana, J., A. Clarke, M. Sarfarazi, N.S.T. Thomas, K. Roberts, K. Marymee, and P.S. Harper. 1988. X-linked hypohidrotic ectodermal dysplasia: localization within the region Xq11-21.1 by linkage analysis and implications for carrier detection and prenatal diagnosis. Am. J. Hum. Genet. 43:75-85.

4. Zonana, J., M. Jones, D. Browne, M. Litt, P. Kramer, H.W. Becker, and N. Brockdorff. 1992. High-resolution mapping of the X-linked hypohidrotic ectodermal dysplasia (EDA) locus. Am. J. Hum. Genet. 51:1036-1046.

5. Zonana, J., J. Gault, K.J.P. Davies, M. Jones, D. Browne, M. Litt, N. Brockdorff, S. Rastan, A. Clarke, and N.S.T. Thomas. 1993. Detection of a molecular deletion at the DXS732 locus in a patient with X-linked hypohidrotic ectodermal dysplasia (EDA), with the identification of a unique junctional fragment. Am. J. Hum. Genet. 52:78-84.

6. Zonana, J., K. Roberts, N.S.T. Thomas, and P.S. Harper. 1988. Recognition and reanalysis of a cell line from a manifesting female with X-linked hypohidrotic ectodermal dysplasia and an X;autosome balanced translocation. $J$. Med. Genet. 25:383-386.

7. Sundberg, J.P. 1994. The Tabby (Ta), Tabby-c $\left(T a^{c}\right)$, and Tabby-J $\left(T a^{J}\right)$ mutations. In Handbook of Mouse Mutations with Skin and Hair Abnormalities. CRC Press, Inc., Boca Raton, FL. 455-462.

8. Kapalanga, J., and S.R. Blecher. 1990. Effect of the X-linked gene Tabby (Ta) on eyelid opening and incisor eruption in neonatal mice is opposite to that of EGF. Development (Camb.). 108:349-355.

9. Blecher, S.R., J. Kapalanga, and D. Lalonde. 1990. Induction of sweat glands by epidermal growth factor in murine X-linked anhidrotic ectodermal dysplasia. Nature (Lond.). 45:542-544.

10. Pathak, B.G., D.J. Gilbert, C.A. Harrison, N.C. Luetteke, X. Chen, M. Klagsbrun, G.D. Plowman, N.G. Copeland, N.A. Jenkins, and D.C. Lee. 1995 Mouse chromosomal location of three EGF receptor ligands: amphiregulin (Areg), betacellulin (Btc), and heparin-binding EGF (Hegf1). Genomics. 28:116-118.

11. MacDermot, K.D., and M. Hulten. 1990. Female with hypohidrotic ectodermal dysplasia and de novo X:9) translocation. Hum. Genet. 84:577-579.

12. Carpenter, G., and S. Cohen. 1976. ${ }^{125}$ I-labeled human epidermal growth factor. Binding, internalization, and degradation in human fibroblasts. J. Cell Biol. 71:159-171.

13. Jansson, J.-O., S. Ekberg, S.B. Hoath, W.G. Beamer, and L.A. Frohman. 1988. Growth hormone enhances hepatic EGFR concentration in mice. $J$. Clin. Invest. 82:1871-1876.

14. Haigler, H.T., F.R. Maxfield, M.C. Willingham, and I. Pastan. 1980. Dansylcadaverine inhibits internalization of ${ }^{125}$ I-epidermal growth factor in Balb 3 T3 cells. J. Biol. Chem. 255:1239-1241.

15. Haigler, H.T., J.A. McKanna, and S. Cohen. 1979. Direct visualization of the binding and internalization of a ferritin conjugate of epidermal growth factor in human carcinoma cells A-431. J. Cell Biol. 81:382-395.

16. Haigler, H.T., D.D. Schlaepfer, and W.H. Burgess. 1987. Characterization of lipocortin I and an unrelated $35-\mathrm{kD}$ a protein as epidermal growth factor receptor/kinase substrates and phospholipase $\mathrm{A}_{2}$ inhibitors. J. Biol. Chem. 262: 6921-6930.

17. Collins, F. 1992. Positional cloning, lets not call it reverse anymore. Nat. Genet. 1:3-6.

18. Carpenter, G. 1987. Receptors for EGF and other polypeptide mitogens. Annu. Rev. Biochem. 56:881-914.

19. Thomas, N.S.T., J. Chelly, J. Zonana, K.J.P. Davies, J. Gault, K.A Rack, V.J. Buckle, N. Brockdorff, A. Clarke, and A. Monaco. 1993. Characterization of molecular DNA rearrangements within the Xq12-q13.1 region, in three patients with X-linked hypohidrotic ectodermal dysplasia (EDA). Hum. Mol. Genet. 2:1679-1685.

20. Wilson, G.N. 1993. Relevance of the genetics of embryologic development. Growth Genetics and Hormones. 9:1-5.

21. Leutteke, N.C., T.H. Qiu, R.L. Peiffer, P. Oliver, O. Smithies, and D.C. Lee. 1993. TGF-alpha deficiency results in hair follicle and eye abnormalities in targeted and Waved-1 mice. Cell. 73:263-278.

22. Leutteke, N.C., H.K. Phillips, T.H. Qiu, N.G. Copeland, H.S. Earp, N.A. Jenkins, and D.C. Lee. 1994. The mouse waved-2 phenotype results from a point mutation in the EGF receptor tyrosine kinase. Genes \& Dev. 8:399-413.

23. Lillien, L. 1995. Changes in retinal cell fate induced by overexpression of EGF receptor. Nature (Lond.). 377:158-162.

24. Carpenter, G., and S. Cohen. 1990. Epidermal growth factor. J. Biol. Chem. 265:7709-7712. 
25. Saga, K., and M. Takahashi. 1992. Immunoelectron microscopic localization of EGF in the eccrine and apocrine sweat glands. J. Histochem. Cytochem. 40:241-249.

26. Nanney, L.B., D.M. Stoscheck, L.E. King, Jr., R.A. Underwood, and K.A. Holbrook. 1990. Immunolocalization of EGF receptors in normal developing human skin. J. Invest. Dermatol. 94:742-748.

27. Miettinen, P., J.E. Berger, J. Meneses, Y. Phung, R.A. Pedersen, Z. Werb, and R. Derynck. 1995. Epithelial immaturity and multiorgan failure in mice lacking epidermal growth factor receptor. Nature (Lond.). 376:337-341.

28. Threadgill, D.W., A.A. Dlugosz, L.A. Hansen, T. Tennenbaum, U. Lichti, D. Yee, C. LaMantia, T. Mourton, K. Herrup, R.C. Harris, et al. 1995. Targeted disruption of mouse EGF receptor: effect of genetic background on mutant phenotype. Science (Wash. DC). 269:230-234.

29. Sibilia, M., and E.F. Wagner. 1995. Strain-dependent epithelial defects in mice lacking the EGF receptor. Science (Wash. DC). 269:234-238.
30. Hirata, Y., and D.N. Orth. 1979. Concentrations of epidermal growth factor, nerve growth factor, and submandibular gland renin in male and female mouse tissue and fluids. Endocrinology. 105:1382-1387.

31. Tsutsumi, O., H. Kurachi, and T. Oka. 1986. A physiological role of epidermal growth factor in male reproductive function. Science (Wash. DC). 233 975-977.

32. Oka, Y., and D.N. Orth. 1983. Human plasma epidermal growth factor/ $\beta$-urogastrone is associated with blood platelets. J. Clin. Invest. 72:249-259.

33. Starkey, R.H., and D.N. Orth. 1977. Radioimmunoassay of human epidermal growth factor (urogastrone). J. Clin. Endocrinol. \& Metab. 45:1144-1153.

34. Gregory, H., J.E. Holmes, and I.R. Willshire. 1977. Urogastrone levels in the urine of normal adult humans. J. Clin. Endocrinol. \& Metab. 45:668-672.

35. Gates, R.E., and L.E. King, Jr. 1982. Calcium facilitates endogenous proteolysis of the EGF receptor-kinase. Mol. Cell. Endocrinol. 27:263-276. 